\title{
Violence among men and women in substance use disorder treatment: A multi-level event-based analysis ${ }^{\text {th }}$
}

\author{
Stephen T. Chermack ${ }^{\mathrm{a}, \mathrm{b}, *}$, Andy Grogan-Kaylor ${ }^{\mathrm{c}}$, Brian E. Perron ${ }^{\mathrm{b}, \mathrm{c}}$, Regan L. Murray ${ }^{\mathrm{d}}$, Peter De Chavez $^{\mathrm{e}}$, \\ Maureen A. Walton ${ }^{\mathrm{a}}$ \\ a University of Michigan Addiction Research Center, Department of Psychiatry, University of Michigan, Ann Arbor, MI 48105, USA \\ b Serious Mental Illness Treatment Research Evaluation Center (SMITREC), VA Ann Arbor Healthcare System, Ann Arbor, MI 48105, USA \\ c University of Michigan School of Social Work, University of Michigan, Ann Arbor, MI 48109, USA \\ d University of Arkansas, Department of Psychology, Fayetteville, AR 72701, USA \\ e Mental Health Services Outcomes and Translation Section, Department of Psychiatry, University of Michigan, Ann Arbor, MI 48105, USA
}

\section{A R T I C L E I N F O}

\section{Article history:}

Received 30 September 2009

Received in revised form 4 June 2010

Accepted 6 June 2010

Available online $\mathrm{xxx}$

\section{Keywords:}

Aggression

Injury

Alcohol

Cocaine

Drugs

Treatment

\begin{abstract}
A B S T R A C T
Background: This study examined associations between acute alcohol and drug use and violence towards others in conflict incidents (overall, partner, and non-partner conflict incidents) by men and women recruited from substance use disorder (SUD) treatment.

Methods: Semi-structured interviews were used to obtain details about interpersonal conflict incidents (substance use, whether specific conflicts were with intimate partners or non-partners) in the 180 days pre-treatment. Participants for this study were selected for screening positive for past-year violence ( $N=160 ; 77 \%$ men, $23 \%$ women).

Results: Multi-level multinomial regression models showed that after adjusting for clustering within individual participants, the most consistent predictors of violence across models were acute cocaine use (significant for overall, intimate partner and non-partner models), acute heavy alcohol use (significant for overall and non-partner models), and male gender (significant in all models).

Conclusions: This study was the first to explicitly examine the role of acute alcohol and drug use across overall, partner and non-partner conflict incidents. Consistent with prior studies using a variety of methodologies, alcohol, cocaine use and male gender was most consistently and positively related to violence severity (e.g., resulting in injury). The results provide important and novel event-level information regarding the relationship between acute alcohol and specific drug use and the severity of violence in interpersonal conflict incidents.
\end{abstract}

(C) 2010 Published by Elsevier Ireland Ltd.

\section{Introduction}

Evidence suggests that substance use disorder (SUD) treatment samples report significantly higher rates of violence than community-based samples (Brown et al., 1998; Chermack et al., 2000; Gondolf and Foster, 1991). The present study focuses on the relationship between alcohol and other drug consumption and violence towards others in specific conflict incidents among men and women in treatment for substance use disorders screening positive for past-year violence. Numerous studies and systematic reviews have documented an association between the frequency of alcohol and other drug use (most notably, cocaine) and violence (Chermack et al., 2008; Lipsey et al., 1997; Moore et al., 2008). A

\footnotetext{
ClinicalTrials.gov Identifier: NCT00551863.

* Corresponding author at: Department of Psychiatry (116C), VA Ann Arbor, 2215 Fuller Road, Ann Arbor, MI 48105, USA. Tel.: +1 734845 3908; fax: +1 7348453235. E-mail address: Chermack@umich.edu (S.T. Chermack).
}

recent meta-analysis by Moore et al. (2008) focusing on the relationship between drug use patterns and intimate partner violence also found positive associations with other types of drugs (i.e., marijuana, opiates). Thus, there is evidence that alcohol and drug use patterns are associated with violence, but that the strength of this association differs for different types of drugs (Moore et al., 2008).

Although studies examining associations between alcohol and drug use patterns and violence provide important information, such methodology has limited capacity with regard to understanding the potential influence of acute alcohol and drug use and violence. It has been argued that the mechanisms underlying such relationships, such as individual difference factors (e.g., age, gender, demographics), pharmacologically based acute/proximal intoxication effects, withdrawal effects, and social/contextual factors (e.g., associated with using, buying, selling and acquiring drugs) likely differ for different types of drugs (Goldstein, 1985; Moore et al., 2008) and could vary over time. Thus, alternative methodologies are indicated to better understand the degree to which acute alco- 
hol and other drug use and violence may be proximally related to violence.

With regard to alcohol use, there is evidence from reviews and meta-analyses of controlled laboratory studies (Bushman and Cooper, 1990; Chermack and Giancola, 1997; Ito et al., 1996), and studies focusing on specific interpersonal conflict incidents that acute alcohol use is associated with aggression/violence (Chermack and Blow, 2002; Leonard and Quigley, 1999; Murphy et al., 2005; Parks et al., 2008; Testa et al., 2003). There is also evidence from controlled laboratory studies (e.g., Licata et al., 1993) and studies of specific violent events in SUD samples (Chermack and Blow, 2002) showing an association between acute cocaine use and aggression. Several theorists have argued that acute pharmacologically based effects of alcohol, such as disruptions in cognitive processing, play a central role in explaining post-drinking aggression (e.g., Chermack and Giancola, 1997; Ito et al., 1996). Similarly, a few theorists have speculated that pharmacological effects of cocaine, such as reductions in the inhibition of aggressive impulses, also play a causal role with regard to aggression (Davis, 1996). However, findings regarding acute use of other drugs (marijuana, opiates) and aggression appear to be more mixed (Berman et al., 1993; Moore and Stuart, 2005; Myerscough and Taylor, 1985). For marijuana use, theorists have speculated that individual difference factors as well as irritability associated with marijuana withdrawal (Moore and Stuart, 2005) may explain the observed associations between marijuana use patterns and violence. For opiate use, it has been speculated that personality factors, withdrawal and social/contextual factors (fights over sharing, buying, selling opiates, violence to acquire drugs or money for drugs) may explain observed associations between opiate use and violence (Goldstein, 1985; Hoaken and Stewart, 2003).

Important limitations of prior studies examining acute alcohol and drug use and violence remain. For example, laboratory research has been criticized for using samples consisting of collegeaged participants (typically males), measures of aggression with questionable construct validity and potentially limited external and ecological validity, and the presence of demand characteristics (Leonard and Senchak, 1996; Tedeschi and Quigley, 1996). Prior studies focusing on specific violent incidents also have had a number of limitations. For example, although several studies have shown an association between acute alcohol and/or drug use and violence severity (Chermack and Blow, 2002; Collins and Schlenger, 1988; Martin and Bachman, 1997), several studies have not examined whether participants' alcohol/drug use on non-conflict days differed significantly from use associated with the violent conflicts. The studies that have addressed such limitations have found that acute drinking and/or drug use (e.g., cocaine) is related to violence severity even after controlling for general use patterns, or by examining levels of use on days that do and do not involve interpersonal conflicts (Chermack and Blow, 2002; Leonard and Quigley, 1999; Parks et al., 2008; Testa et al., 2003). However, these studies also have important limitations. For example, some studies focused on a limited set of drugs (e.g., alcohol only, alcohol and cocaine only) (Chermack and Blow, 2002; Chermack et al., 2006; Parks et al., 2008) or collapsed across different types of drugs (Murphy et al., 2005), and were thus unable to assess potential unique effects of other drugs. Other limitations include focusing exclusively on overall violence (collapsing across incidents involving intimate partners and/or non-partners) (Chermack and Blow, 2002; Chermack et al., 2006), using measures of violence involvement that do not distinguish between perpetration and victimization (Parks et al., 2008), or focusing exclusively on partner violence (Leonard and Quigley, 1999; Murphy et al., 2005; Testa et al., 2003). Finally, several studies did not measure violence resulting in physical injury (Chermack and Blow, 2002; Chermack et al., 2006; Murphy et al., 2005; Testa et al., 2003), a variable often revealing gender differences in vio- lence compared to commonly used measures of physical aggression (Chermack et al., 2009).

The purpose of this study is to examine the relationship between alcohol and other drug consumption among individuals in treatment for substance use disorders and the severity of violence towards others in specific conflict incidents. This study addressed limitations of prior research by including both men and women, and including both measures of physical violence and violence resulting in injury. Further, we conducted analyses examining overall conflict incidents (collapsing across partner and non-partner incidents), as well as incidents involving intimate partners and non-partners. The analysis includes both bivariate statistics as well as a primary multinomial multi-level regression model as a means of illustrating potential similarities and differences in the pattern of relationships between acute alcohol and drug use and violence (violence, violence with injury) depending on analytic approaches. Specifically, the primary multinomial multi-level regression analysis strategy accounted the potential impact of alcohol and specific drugs on violence by estimating person specific relationships between acute alcohol and drug use and violence severity, after adjusting for individual difference factors (e.g., age, race, gender). It was hypothesized that for substance use variables, acute alcohol and cocaine use would be positively associated with violence measures (because this is the first study of SUD samples conflict incidents to examine overall, partner and non-partner incidents, we did not make specific hypotheses regarding whether the relationships with alcohol and drug use and violence would differ depending on relationship type). In terms of other participant factors, based on prior studies it was anticipated that younger age (e.g., Chermack and Blow, 2002; Moore et al., 2008) and male gender would be related to violence measures. More specifically with regard to gender, based on prior studies (Cantos et al., 1994; Cascardi et al., 1992; Chermack et al., 2009; Hamby, 2005), it was anticipated that male gender would be related to violence resulting in injury.

\section{Methods}

\subsection{Study recruitment}

The current study involved participants who were screened and assessed to participate in a randomized control pilot study (RCT) of a brief violence prevention intervention for men and women in SUD treatment. Participants were recruited from substance use disorder treatment programs, including community residential centers, intensive outpatient, and regular outpatient settings. Approximately $95 \%$ of persons approached agreed to participate in the initial screening survey, producing a screening sample of 489 participants (see Chermack et al., 2008 for additional information regarding the screening sample). To be eligible for participating in the $\mathrm{RCT}$, inclusion criteria included reporting a positive history for past-year physical aggression according to a modified Conflict Tactics Scale-II (CTS-II; see Section 2.2 for additional information), living within the study catchment area (45 mile radius of the study sites, an urban area in the Midwest of the United States), and being new to treatment (recruited within 30 days of starting treatment). Exclusion criteria included the presence of psychotic symptoms, significant cognitive impairments, and/or being an IV heroin user or on opiate agonist treatment. Overall, 352 (75\%) participants from the screening sample reported past-year violence, but only 205 met the remainder of the inclusion for the baseline assessment (excluded due to distance $=81$, in treatment center too long $=30$; heroin dependence $/$ methadone $=11$; schizophrenia diagnosis $=17$; refused further participation/dropped out of treat ment $=8$ ). Approximately 95\% ( $n=194)$ of those eligible for the baseline assessment completed at least part of our baseline assessment (e.g., self-report measures). The baseline assessment also included a detailed semi-structured interview regarding alcohol and drug use as well as involvement with specific interpersonal conflict incidents during the 180 days prior to treatment. Data for the present study are derived from information gathered from those participants $(n=178)$ completing the detailed semi-structured interviews as part of the baseline assessment.

\subsection{Measurement}

2.2.1. Alcohol and drug consumption. Timeline Follow Back (TLFB) semi-structured interviews (Sobell et al., 1979) were used to assess alcohol and drug use patterns during the 180 days prior to treatment. The TLFB examines daily alcohol and drug consumption over a specified interval (e.g., 90-180 days) using monthly calendars 
(Sobell et al., 1979). Several studies have demonstrated this measure has good reliability and validity (Maisto et al., 1979; Sobell et al., 1979, 1988). For the present study, the following variables were abstracted from the TLFB: percentage of days of heavy drinking ( 5 or more drinks), percentage of days involving cocaine use, marijuana use and heroin use. For the purposes of data analysis (e.g., comparison of consumption on conflict and non-conflict days), the computation of the TLFB alcohol and drug use pattern measures did not include days in which participants reported a significant conflict situation. Thus, these measures were labeled "non-conflict days" alcohol and drug (marijuana, cocaine, opiates) consumption, respectively (description of alcohol and drug use measures for conflict days is described in the following section).

2.2.2. Violence. The Time Line Follow Back-Aggression Module (TLFB-AM) was used to assess specific interpersonal conflict incidents. The TLFB-AM was developed to be used in conjunction with the Time Line Follow Back substance use assessment (TLFB-see above) (Chermack and Blow, 2002; Chermack et al., 2006), and the prior findings have been highly consistent with prior studies using a variety of methodologies and samples (e.g., SUD samples, controlled laboratory studies, epidemiological samples), and theories regarding the relationship between substance use and violence (Chermack and Giancola, 1997; Chermack and Taylor, 1995; Licata et al., 1993; Moore et al., 2008). The TLFB-AM asks participants to identify specific dates in a specified time interval (typically 90-180 days) in which they experienced interpersonal conflict. For each of these conflict incident days, participants are asked about the setting of the conflict (home, bars, work, "the streets," etc.), and their relationship with the other person (e.g., spouse, girlfriend/boyfriend, friend, stranger, co-worker, etc.). Next, they are given a list of specific aggressive behaviors adapted from the physical assault and injury scales of Conflict Tactics Scale-2 (CTS-2) (Straus et al., 1996), and are asked to identify whether each of the aggressive acts occurred during the conflict for both themselves and the other person involved with the conflict (thus assessing both violence towards others and victimization). From participant responses, each conflict incident was categorized as involving no violence, physical violence (based on physical assault scale items) and physical violence with injury (the presence of physical violence plus injury based on CTS-2 injury scale items) (Straus et al., 1996). To assess conflict day alcohol and drug use, participants are also asked about their own alcohol use (number of drinks) and drug use (e.g., cocaine, marijuana, heroin, etc.). Thus, from the TLFB-AM, we derived categorical measures of violence (no violence, violence without injury, violence with injury) for overall incidents (collapsing across relationship type), incidents with intimate partners, and incidents with non-partners.

2.2.3. Additional measures. The initial screening survey included brief measures of demographics (age, race, and sex) (for details, see Chermack et al., 2008; Murray et al., 2008). Finally, the Substance Abuse Outcomes Module was used to assess consequences related to substance use (Smith et al., 1996). The SAOM consequences scale is a 25-item self-report measure designed to assess the severity of alcohol and drug problems in the past year and has excellent psychometric properties (Smith et al., 1996, 2006), including excellent internal consistency (coefficient alpha $>0.93$ for the alcohol and drug consequences scales) (Chermack et al., 2000). Participants are asked to indicate whether they experienced a series of 25 substance-related consequences in the past year and whether the consequence was due to alcohol and/or other drugs

\subsection{Data analysis}

The analysis approach included both simple descriptive statistics as well as a primary multinomial multi-level regression models to illustrate potentially inconsistencies regarding the pattern of relationships between acute alcohol and drug use and violence (i.e., violence without injury and violence with injury for overall, partner and non-partner conflict incidents) depending on analytic approaches. Thus, the relationship between violence in conflict incidents and substance use for both conflict and non-conflict days were first examined using univariate and bivariate statistics. Such analyses illustrate relationships between alcohol and other drug use and violence that are unadjusted for other covariates, or for the fact that there are repeated observations for each study participant. Next, multivariate multi-level multinomial logistic regression was used to examine the associations between different types of substances and violence in conflict incidents, with separate models examining overall conflict incidents, intimate partner incidents, and non-partner incidents. Equations were estimated to examine the predictors of violence without injury and violence with injury; "no violence" response served as the reference category. The use of multinomial models meant no ordering of violence severity across the outcome categories was assumed. To provide a more intuitive presentation of these results, the estimates are presented as adjusted odds ratios (AOR) with $95 \%$ confidence intervals $(\mathrm{CI})$. Finally, because individual conflict incidents were nested within individuals, models failing to account for such clustering might provide biased estimates of coefficients and standard errors. In order to account for this clustering, we estimated a multi-level multinomial logistic regression to account for the nesting of measurement occasions inside individuals (Raudenbush and Bryk, 2002). We employed HLM (Raudenbush et al., 2001) to estimate these models.

\section{Results}

\subsection{Sample description}

The age of participants ranged from 18 to 63 years, with a mean (SD) of 35.6 (10.8) years. With regard to ethnicity, most of the study participants were Caucasian (48\%), with the remaining participants of African-American (37\%), and 15\% other ethnicities. Approximately $12 \%$ were married, $4 \%$ separated, $18 \%$ divorced, $1 \%$ widowed, $13 \%$ with a significant other and $52 \%$ never married. Overall, 31\% reported that they were presently living with their spouse/partner. Regarding education, $6 \%$ had less than an eighth grade education, $40 \%$ attended (but did not graduate) high school, $25 \%$ graduated from high school, 25\% attended college, and $4 \%$ graduated from college. According to the SAOM past-year consequences scale, $72 \%$ reported alcohol consequences, $70 \%$ cocaine consequences, $41 \%$ marijuana consequences and $27 \%$ opiate consequences. Finally, according to the TLFB measuring substance use in the 180 days prior to treatment, $62 \%$ reported any alcohol use, $50 \%$ reported heavy drinking, $61 \%$ cocaine use, 36\% marijuana use, and $13 \%$ heroin use.

\subsection{Descriptive analysis}

In terms of overall violence, according to the TLFB-AM 50\% of the sample reported 1 or more incidents of violence towards others during the 180 days prior to treatment [mean $(\mathrm{SD})=3.4$ (11.1) physical assault incidents], and 20\% reported injuring another person [mean $(S D)=1.3(8.0)$ injury incidents]. For partner violence, 19\% reported 1 or more incidents of violence [mean $(S D)=1.8(8.6)$ physical assault incidents] and 3\% reported injuring their partner [mean $(S D)=0.6$ (7.2) injury incidents], whereas for non-partner violence $31 \%$ reported 1 or more incidents of violence [mean $(\mathrm{SD})=0.8(2.8)$ physical assault incidents] and $14 \%$ reported injuring a non-partner [mean $(\mathrm{SD})=0.4$ (2.6) injury incidents]. On days involving interpersonal conflicts (collapsing across relationship type and regardless of whether violence occurred), the mean (SD) number of drinks per day was 4.9 (7.4); and the percent days of marijuana, cocaine and heroin use were $41 \%, 61 \%$ and $15 \%$, respectively. On non-conflict days assessed with the TLFB, the mean (SD) number of drinks per day was 2.0 (4.7); and the percent days of marijuana, cocaine and heroin use were $13 \%, 17 \%$ and $4 \%$, respectively. Such descriptive data suggest that both alcohol and other drug use appeared to be higher, or more likely, on days involving interpersonal conflicts.

Table 1 illustrates the unadjusted bivariate relationships between violence (without and with injury) towards others (overall, partner and non-partner) and acute substance use (i.e., alcohol, cocaine, marijuana, heroin) on days with interpersonal conflicts. For alcohol use, moderate levels of alcohol consumption (i.e., 1-5 drinks) appeared related to higher rates of violence and violence resulting in injury for overall conflict incidents and non-partner incidents, but the absence of alcohol use appeared related to higher rates of partner violence and injury. For marijuana, across overall-, partner and non-partner conflict incidents, rates of both violence without injury and violence with injury appeared markedly lower in incidents involving acute marijuana use. Acute cocaine use appeared consistently related to violence with injury across overall-, partner and non-partner conflict incidents, whereas acute heroin use appeared associated with violence (particularly resulting in injury) for overall and partner incidents. However, these findings clearly must be interpreted cautiously as they are not adjusted for respondent characteristics or the fact that observations are clustered within individuals. 
Table 1

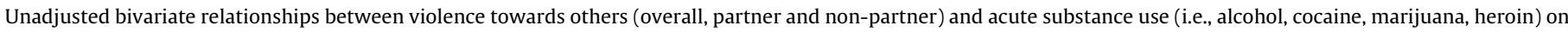
days with interpersonal conflicts.

\begin{tabular}{|c|c|c|c|c|c|c|c|c|c|c|c|c|}
\hline & \multicolumn{4}{|c|}{ Overall conflict incidents } & \multicolumn{4}{|c|}{ Partner conflict incidents } & \multicolumn{4}{|c|}{ Non-partner conflict incidents } \\
\hline & $\begin{array}{l}\text { No } \\
\text { violence }\end{array}$ & $\begin{array}{l}\text { Violence } \\
\text { without } \\
\text { injury }\end{array}$ & $\begin{array}{l}\text { Violence } \\
\text { with } \\
\text { injury }\end{array}$ & $\begin{array}{l}\text { Chi-square } \\
\text { value }\end{array}$ & $\begin{array}{l}\text { No } \\
\text { violence }\end{array}$ & $\begin{array}{l}\text { Violence } \\
\text { without } \\
\text { injury }\end{array}$ & $\begin{array}{l}\text { Violence } \\
\text { with } \\
\text { injury }\end{array}$ & $\begin{array}{l}\text { Chi-square } \\
\text { value }\end{array}$ & $\begin{array}{l}\text { No } \\
\text { violence }\end{array}$ & $\begin{array}{l}\text { Violence } \\
\text { without } \\
\text { injury }\end{array}$ & $\begin{array}{l}\text { Violence } \\
\text { with } \\
\text { injury }\end{array}$ & $\begin{array}{l}\text { Chi-square } \\
\text { value }\end{array}$ \\
\hline \multicolumn{13}{|l|}{ Alcohol $^{\mathrm{a}}$} \\
\hline No drinks & 56.49 & 28.93 & 14.58 & $42.87^{*}$ & 45.52 & 30.02 & 24.46 & $92.11^{*}$ & 66.38 & 27.95 & 5.68 & $146.77^{*}$ \\
\hline Moderate & 46.85 & 25.23 & 27.93 & & 69.84 & 30.16 & 0.00 & & 16.67 & 18.75 & 64.58 & \\
\hline Heavy & 69.23 & 18.96 & 11.81 & & 73.43 & 23.78 & 2.80 & & 64.84 & 13.92 & 21.25 & \\
\hline \multicolumn{13}{|l|}{ Marijuana } \\
\hline No marijuana & 45.93 & 30.22 & 23.85 & $229.10^{*}$ & 43.10 & 31.19 & 25.71 & $125.17^{*}$ & 48.37 & 29.39 & 22.24 & $117.25^{*}$ \\
\hline Marijuana & 80.98 & 17.75 & 1.27 & & 76.32 & 23.39 & 0.29 & & 86.51 & 11.07 & 2.42 & \\
\hline \multicolumn{13}{|l|}{ Cocaine } \\
\hline No cocaine & 60.33 & 34.05 & 5.62 & $86.70^{*}$ & 56.00 & 41.00 & 3.00 & $41.76^{*}$ & 62.47 & 30.62 & 6.91 & $60.09^{*}$ \\
\hline Cocaine & 60.26 & 19.34 & 20.41 & & 58.72 & 22.95 & 18.33 & & 62.57 & 13.90 & 23.53 & \\
\hline \multicolumn{13}{|l|}{ Heroin } \\
\hline No heroin & 65.48 & 24.87 & 9.66 & $190.33^{*}$ & 69.88 & 27.81 & 2.32 & $265.31^{*}$ & 62.20 & 22.68 & 15.12 & 1.27 \\
\hline Heroin & 30.09 & 26.55 & 43.36 & & 24.88 & 27.36 & 47.76 & & 72.00 & 20.00 & 8.00 & \\
\hline
\end{tabular}

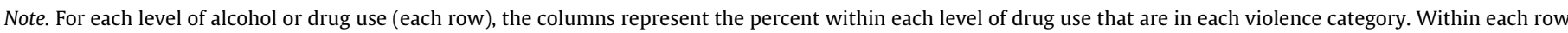

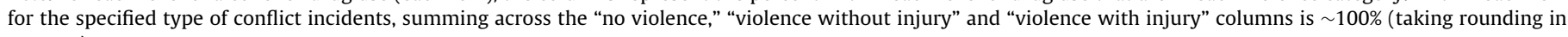
account).

a Moderate =1-4 drinks for women; 1-5 for men; heavy drinking = 5 or more for women; 6 or more for men.

* $p<0.001$.

\subsection{Multivariate analysis: models predicting violence without} injury and violence with injury for overall conflict incidents, partner incidents and non-partner incidents

As previously described, all three models had a three-category outcome, where the odds of violence without injury and violence resulting in injury are estimated in comparison to no injury (see Table 2). The regression model for overall conflict incidents showed that violence without injury was not associated with age or race. However, males had significantly higher odds of violence without injury ( $\mathrm{AOR}=6.21,95 \% \mathrm{CI}=1.66-23.63)$ compared to females, and acute cocaine use $(\mathrm{AOR}=11.26,95 \% \mathrm{CI}=5.10-24.86)$ and acute heroin use $(\mathrm{AOR}=16.04,95 \% \mathrm{CI}=1.26-204.36)$ both were significantly associated with violence without injury. Similar results were observed for violence with injury compared to no violence. More specifically, age and race were not statistically significantly associated with violence with injury. However, males had significantly higher odds $(\mathrm{AOR}=6.45,95 \% \mathrm{CI}=1.31-31.34)$ of reporting violence resulting in injury compared to females. In terms of acute alcohol and drug use, a higher likelihood of violence resulting in injury was observed for both cocaine $(A O R=6.72,95 \% C I=2.12-21.30)$ and heavy drinking $(\mathrm{AOR}=6.01,95 \% \mathrm{CI}=1.65-21.83)$.

The model for conflict incidents with a partner revealed only a few statistically significant findings, with only Male gen$\operatorname{der}(\mathrm{AOR}=35.31,95 \% \mathrm{CI}=1.10-1131.43)$ and acute cocaine use ( $A O R=116.51,95 \% \mathrm{CI}=20.478-662.971$ ) being related to violence without injury (caution is clearly indicated in interpreting the partner violence model in terms of the strength of the association between cocaine use and violence given the high AOR and wide confidence interval). However, the model for conflict incidents with non-partners provided interesting results. Male gen$\operatorname{der}(\mathrm{AOR}=6.29,95 \% \mathrm{CI}=1.65-24.54)$ and cocaine use $(\mathrm{AOR}=3.59$, 95\% $\mathrm{CI}=1.31-9.83$ ) increased the odds of violence without injury. Further, male gender $(\mathrm{AOR}=14.67,95 \% \mathrm{CI}=2.31-93.29$ ), being of another race or ethnicity (e.g., non-African-American) ( $A O R=8.85,95 \% \mathrm{CI}=1.60-48.93$ ), acute cocaine use (AOR $=5.53$, $95 \% \mathrm{CI}=1.62-18.96$ ), and acute heavy drinking ( $\mathrm{AOR}=11.50,95 \%$ $\mathrm{CI}=3.04-43.47)$ all increased the likelihood of violence with injury, whereas acute marijuana use ( $\mathrm{AOR}=0.12,95 \% \mathrm{CI}=0.02-0.74$ ) decreased the odds of violence with injury.
Finally, to further explore potential gender related effects, we conducted supplementary exploratory models to examine whether gender appeared to moderate the impact of the alcohol and drug use variables on violence outcomes. These models expanded on the analyses described above by adding interaction terms of gender with each substance (alcohol, cocaine, marijuana, heroin). However, in each analysis there were no significant interactions with gender and alcohol or drug use variables.

\section{Discussion}

The present study examined the relationships between acute use of alcohol and other drugs and violence towards others in specific conflict incidents among men and women in SUD treatment. The study addresses a number of limitations of prior research by including both men and women in the sample, measures of both violence and violence resulting in injury, the inclusion of measures of acute use of alcohol and several other drugs (cocaine, marijuana, heroin), as well as analyses specifically examining overall conflict incidents, incidents involving intimate partners, and incidents involving non-partners. Further, the analysis strategy revealed the importance of using statistical approaches that account for individual difference factors and repeated measurement on the same individuals. For example, unadjusted bivariate analyses revealed significant associations between alcohol and each type of drug and measures of violence. However, such analyses suggested that in general, acute moderate alcohol consumption (with the exception of partner incidents), cocaine and heroin use were associated with violence, and that marijuana use appeared related to less severe violence. The bivariate findings regarding acute alcohol use in particular appear to be inconsistent with prior research (both experimental laboratory studies and studies of SUD samples) which has tended to find higher levels of drinking (heavy or "binge" drinking) to be associated with aggression/violence (compared to no drinking or more moderate use) (Chermack and Blow, 2002; Ito et al., 1996; Murphy et al., 2005).

In contrast, the multivariate analyses adjusted for demographics, the impact of specific substances while adjusting for use of other substances, and repeated measurement of individuals. The multivariate models illustrated that acute heavy alcohol use and 


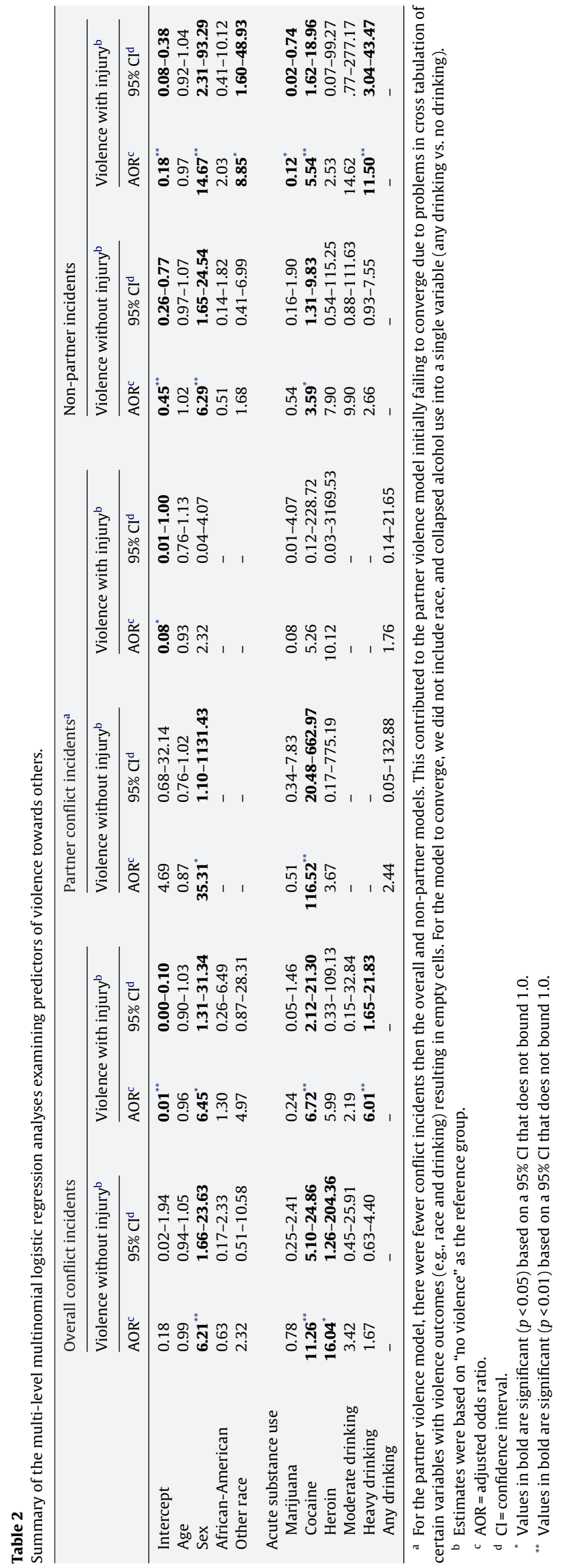

cocaine use in particular were positively associated with violence [although contrary to expectations and prior findings with SUD or married partner samples (e.g., Chermack and Blow, 2002; Leonard and Quigley, 1999), alcohol use was not related to partner violence in our sample]. Thus, an important feature of this study is that it took into account the nested data structure (i.e., multiple observations for respondents). As prior studies have demonstrated, failing to account for nesting can produce standard errors that are under-estimated, thereby increasing the likelihood of a Type I error. Moreover, it is also possible that the direction of effects can also change when a model accounts for clustering. In this study, important changes were observed with respect to acute effects of alcohol in particular. More notably, heavy alcohol use appeared associated with lower rates of violence with injury at the bivariate level but was a significant correlate of violence with injury (with the exception of partner conflict incidents) at the multivariate level. This pattern of findings in the multivariate analysis appears more consistent with prior controlled experimental studies and the relatively few studies that have examined the relationship between acute alcohol and drug use and violence (Berman et al., 1993; Chermack and Blow, 2002; Ito et al., 1996; Licata et al., 1993; Murphy et al., 2005; Myerscough and Taylor, 1985; Parks et al., 2008). Further, the finding that heavy drinking generally was related to violence with injury after adjusting for the impact of other substances highlights the strength of this association. It should be noted that our analysis strategy illustrates that within a single study sample, seemingly inconsistent patterns of findings can occur depending on analysis strategy, but that overall, acute heavy alcohol use and cocaine use in particular are substances that appear proximally associated with violence in SUD samples.

The pattern of findings is consistent with, and provides some additional support for pharmacologically based explanations of the relationship between certain substances (alcohol and cocaine) and violence. For example, theorists have argued that alcohol use impairs cognitive processing (i.e., attentional processes, problem solving, disruptions in generating response alternatives, evaluating consequences of response alternatives and/or thinking through consequences of actions), which increases the likelihood of violence (Chermack and Giancola, 1997; Sayette et al., 1993). With regard to pharmacologically based explanations of the relationship between cocaine use and violence, researchers have suggested that this may be attributed at least in part to the impact of cocaine on seratonergic functioning and/or other states associated with cocaine use (irritability, anxiety, paranoia, impaired impulse control) (Davis, 1996; Moore et al., 2008). Finally, heroin use was more likely on conflict days, and acute heroin use was positively associated with overall violence without injury (very few studies have examined the acute impact of opiate use on violence, and one controlled laboratory study found increased aggression with morphine; (Berman et al., 1993). Nevertheless, this pattern of findings is inconsistent with opiate withdrawal explanations of the relationship between heroin use and violence and suggests that it is possible that acute pharmacological effects of heroin may contribute to violence risk. It should be noted, however, that with the present study, it is not possible to rule out other potential factors that could account for the observed relationships between alcohol, cocaine use (and to a lesser extent, heroin use) and violence. For example, it is possible that other social and contextual factors associated with acute alcohol, cocaine or heroin use (disputes over buying, selling or sharing drugs; conflicts due to others being upset with participants use of alcohol, cocaine or heroin; more frequent exposure to such high risk situations for violence) play a role in accounting for the observed associations. Finally, the unexpected lack of a relationship between alcohol use and violence and the strength of the association between cocaine use and violence in partner incidents both should be interpreted with some caution. In contrast to most prior 
studies (e.g., Leonard and Quigley, 1999; O’Farrell et al., 2004; Testa et al., 2003), the present sample was not selected based on partner status (either having a partner, or reporting violence in partner relationships). Further, the partner model was based on fewer conflict incidents than the other models, and we also needed to make some adjustments for this model to converge. It is possible, though, that the partner model findings may illustrate that social and contextual/situational influences may have a more potent influence on partner violence in conflict incidents. Clearly, additional research is needed to better understand social/contextual factors related to violence, and whether such factors interact with alcohol and other drug use.

With regard to the findings regarding acute marijuana use and violence, for several reasons the findings appear inconsistent with both proposed explanations based on either acute pharmacologically based or withdrawal related effects (Moore and Stuart, 2005). Specifically, although there was evidence that marijuana use was more likely on conflict days, acute marijuana was not positively associated with increased odds of physical violence or injury in multivariate analyses (and marijuana use was related to decreased likelihood of violence with injury in non-partner conflict incidents). The present findings suggest that other factors likely account for observed associations between marijuana use patterns and violence, such as personality (e.g., general aggressiveness), expectancies about drug effects, and/or social contextual factors associated with general marijuana use. For example, marijuana use patterns have been associated with expectancies that marijuana reduces negative affect (Martens and Gilbert, 2008), thus it is possible that aggressive individuals may use marijuana frequently due to beliefs that such drugs may help them avoid anger or other negative emotions, and/or dampen aggressive impulses. Further, acute use of marijuana may occur in social contexts that are at enhanced risk for violence (e.g., buying/selling drugs, interactions with aggressive individuals, acute use of alcohol and/or cocaine), and/or those that use marijuana frequently may be more frequently exposed to such high risk situations (whether or not intoxicated on marijuana).

Finally, among demographic variables examined, gender was related to violence, with male gender being generally associated with violence with and without injury. The finding regarding injury appears consistent with prior studies suggesting males are more likely to injure others in violent conflicts (Cantos et al., 1994; Cascardi et al., 1992; Chermack et al., 2009; Hamby, 2005), although the finding that male gender was associated with violence without injury in partner incidents differs from other studies that have shown similar rates for men and women in terms of past-year physical aggression towards intimate partners (Archer, 2000; Chermack et al., 2001; Walton et al., 2002). Similar rates of violence for men and women appear more likely to be observed when studies do not assess injury and/or do not focus on measures of specific intimate partner conflict incidents. Finally, consistent with similar prior research with a SUD sample (e.g., Chermack et al., 2006) supplemental analysis found no evidence suggestion interactions involving gender and substance use variables, suggesting that both gender and substance use variables appear related to violence, and that the associations of acute alcohol and drug use with violence appears similar for men and women in SUD treatment.

The lack of a relationship between age and violence was somewhat surprising given that studies typically show that younger age is associated with violence (e.g., Chermack and Blow, 2002; Moore et al., 2008), and may reflect that the relationship between age and violence is mitigated by adjusting for several other factors (gender, clustering within individuals, acute alcohol and drug use). Finally, findings regarding race and violence have been somewhat mixed in the literature [e.g., some studies find minority status is related to violence, some do not, some find that race effects appear mediated (partially or fully) by other factors (Caetano et al., 2001, 2005;
Chermack et al., 2000, 2001; Field and Caetano, 2004)], and we found only that non-African-American minority status was associated with violence with injury in non-partner incidents. Additional research with samples including sufficient numbers of a variety of minority participants is needed to more explicitly focus on race and cultural factors as they may be related to violence.

Although this study addressed a number of limitations of prior research, there are several notable limitations. For example, the TLFB-AM did not assess other factors potentially related to violence risk, such as information regarding participants emotional state, and potential motivational and social/contextual factors [e.g., violence to obtain money for drugs, fights over buying/selling/sharing drugs, fights due to other interpersonal stressors associated with substance use (financial problems, neglect of social responsibilities), desire to establish control/dominance in relationships, escalatory processes, etc.]. Thus, future studies should obtain further details regarding violent events, including the role of motivational and emotional factors, reasons for conflict, alcohol and other drug use by both parties, social/contextual factors (setting and other situational factors) and escalatory processes in order to better understand the complex inter-relationships among pharmacological, individual difference and social/contextual factors related to violence. Further, the present multivariate analyses focused on examining main effects of demographics and the role of each substance in terms of individual contribution to violence risk, and thus it is possible that there could be potential interactions among such variables in relationship to violence. Future studies, likely involving larger sample sizes, could provide useful information regarding potential mediating and/or moderating relationships (e.g., age by substance use, interactions among different types of substances). Finally, the present study relied on detailed retrospective self-report information rather than a prospective or controlled design, which limits the ability to infer causation regarding acute alcohol and drug use and violence. Thus, although the present findings highlight the relationships between acute alcohol and drug use (most notably, cocaine) and violence and are consistent with prior research findings using a variety of methodologies (including controlled experimental studies), it is possible that factors other than pharmacologically based effects, such as acute social/contextual factors, mediate the observed relationships between acute alcohol and drug use and violence.

To summarize, the present findings highlight the relative importance of acute heavy alcohol use and particularly cocaine use in terms of factors associated with violence across relationship types among men and women in SUD treatment. The overall pattern of findings for alcohol and cocaine appear to be consistent with prior studies and with pharmacologically based explanations of the manner in which use of such substances may be related to violence. The findings also illustrate significant gender differences when examining specific conflict incidents, with male gender being related to the majority of violence outcomes (without and with injury). Finally, additional research is needed to further understand the interrelationships among and relative impact of demographics, various substances and social, motivational and situational/contextual factors that may impact violence in interpersonal conflict incidents.

\section{Role of funding source}

Funding for this study was provided by NIDA R01 DA01729501A1. NIDA had no further role in study design; in the collection, analysis and interpretation of data; in the writing of the present paper; or in the decision to submit the paper for publication. Preparation of this manuscript also was supported by an institutional grant from the Curtis Center of the University of Michigan, School of Social Work. The views expressed in this article are those of the 
authors and do not necessarily represent the views of NIDA, the University of Michigan or the Curtis Center, the University of Arkansas, or the Department of Veterans Affairs.

\section{Contributors}

The first author (Dr. Chermack) was responsible for designing the overall study from which the data were derived. All authors participated in conceptualizing the current study and preparation of the manuscript. The first three authors (Drs. Chermack, GroganKaylor and Perron), as well as Peter De Chavez were responsible for all data management and analysis. All authors contributed to the writing of the manuscript, and reviewed and approved the analyses and final manuscript.

\section{Conflict of interest}

None of the authors has any financial interests or relationships relevant to the subject of this manuscript.

\section{References}

Archer, J., 2000. Sex differences in aggression between heterosexual partners: a meta-analytic review. Psychol. Bull. 126, 651-680.

Berman, M., Taylor, S., Marged, B., 1993. Morphine and human aggression. Addict. Behav. 18, 263-268.

Brown, T.G., Werk, A., Caplan, T., Shields, N., Seraganian, P., 1998. The incidence and characteristics of violent men in substance abuse treatment. Addict. Behav. 23, 573-586.

Bushman, B.J., Cooper, H.M., 1990. Effects of alcohol on human aggression: an integrative research review. Psychol. Bull. 107, 341-354.

Caetano, R., Field, C.A., Ramisetty-Mikler, S., McGrath, C., 2005. The 5-year course of intimate partner violence among White, Black, and Hispanic couples in the United States. J. Interpers. Violence 20, 1039-1057.

Caetano, R., Schafer, J., Cunradi, C.B., 2001. Alcohol-related intimate partner violence among white, black, and Hispanic couples in the United States. Alcohol Res. Health 25, 58-65.

Cantos, A.L., Neidig, P.H., O'Leary, K.D., 1994. Injuries of women and men in a treatment program for domestic violence. J. Fam. Violence 9, 112-124.

Cascardi, M., Langhinrichsen, J., Vivian, D., 1992. Marital aggression, impact, injury, and health correlates for husbands and wives. Arch. Intern. Med. 152, 1178-1184.

Chermack, S.T., Blow, F.C., 2002. Violence among individuals in substance abuse treatment: the role of alcohol and cocaine consumption. Drug Alcohol Depend. $66,29-37$.

Chermack, S.T., Fuller, B.E., Blow, F.C., 2000. Predictors of expressed partner and nonpartner violence among patients in substance abuse treatment. Drug Alcohol Depend. 58, 43-54

Chermack, S.T., Giancola, P.R., 1997. The relation between alcohol and aggression: an integrated biopsychosocial conceptualization. Clin. Psychol. Rev. 17, 621649.

Chermack, S.T., Murray, R.L., Walton, M.A., Booth, B.A., Wryobeck, J., Blow, F.C., 2008. Partner aggression among men and women in substance use disorder treatment: correlates of psychological and physical aggression and injury. Drug Alcohol Depend. 98, 35-44.

Chermack, S.T., Murray, R.L., Winters, J.J., Walton, M.A., Booth, B.M., Blow, F.C., 2009. Treatment needs of men and women with violence problems in substance use disorder treatment. Subst. Use Misuse 44, 1236-1262.

Chermack, S.T., Taylor, S.P., 1995. Alcohol and human physical aggression: pharmacological versus expectancy effects. J. Stud. Alcohol 56, 449-456.

Chermack, S.T., Walton, M.A., Fuller, B.E., Blow, F.C., 2001. Correlates of expressed and received violence across relationship types among men and women substance abusers. Psychol. Addict. Behav. 15, 140-151.

Chermack, S.T., Wryobeck, J.M., Walton, M.A., Blow, F.C., 2006. Distal and proximal factors related to aggression severity among patients in substance abuse treatment: family history, alcohol use and expectancies. Addict. Behav. 31, 845-858.

Collins, J.J., Schlenger, W.E., 1988. Acute and chronic effects of alcohol use on violence. J. Stud. Alcohol 49, 516-521.

Davis, W.M., 1996. Psychopharmacologic violence associated with cocaine abuse: kindling of a limbic dyscontrol syndrome? Prog. Neuropsychopharmacol. Biol. Psychiatry 20, 1273-1300.

Field, C.A., Caetano, R., 2004. Ethnic differences in intimate partner violence in the U.S. general population: the role of alcohol use and socioeconomic status. Trauma Violence Abuse 5, 303-317.
Goldstein, P.J., 1985. The drug/violence nexus: a tripartite conceptual framework. J. Drug Issues 15, 493-506.

Gondolf, E.W., Foster, R.A., 1991. Wife assault among VA alcohol rehabilitation patients. Hosp. Community Psychiatry 42, 74-79.

Hamby, S.L., 2005. Measuring gender differences in partner violence: implications from research on other forms of violence socially undesirable behavior. Sex Roles 52, 725-742.

Hoaken, P.N., Stewart, S.H., 2003. Drugs of abuse and the elicitation of human aggressive behavior. Addict. Behav. 28, 1533-1554.

Ito, T.A., Miller, N., Pollock, V.E., 1996. Alcohol and aggression: a meta-analysis on the moderating effects of inhibitory cues, triggering events, and self-focused attention. Psychol. Bull. 120, 60-82.

Leonard, K.E., Quigley, B.M., 1999. Drinking and marital aggression in newlyweds: an event-based analysis of drinking and the occurrence of husband marital aggression. J. Stud. Alcohol 60, 537-545.

Leonard, K.E., Senchak, M., 1996. Prospective prediction of husband marital aggression within newlywed couples. J. Abnorm. Psychol. 105, 369-380.

Licata, A., Taylor, S., Berman, M., Cranston, J., 1993. Effects of cocaine on human aggression. Pharmacol. Biochem. Behav. 45, 549-552.

Lipsey, M.W., Wilson, D.B., Cohen, M.A., Derzon, J.H., 1997. Is there a causal relationship between alcohol use and violence? A synthesis of evidence. Recent Dev. Alcohol. 13, 245-282.

Maisto, S.A., Sobell, M.B., Cooper, A., Sobell, L.C., 1979. Test-retest reliability of retrospective self-reports in three populations of alcohol abusers. J. Behav. Assess. $1,315-326$.

Martens, K.M., Gilbert, D.G., 2008. Marijuana and tobacco exposure predict affectregulation expectancies in dual users. Addict. Behav. 33, 1484-1490.

Martin, S.E., Bachman, R., 1997. The relationship of alcohol to injury in assault cases. Recent Dev. Alcohol. 13, 41-56.

Moore, T.M., Stuart, G.L., 2005. A review of the literature on marijuana and interpersonal violence. Aggress. Violent Behav. 10, 21.

Moore, T.M., Stuart, G.L., Meehan, J.C., Rhatigan, D.L., Hellmuth, J.C., Keen, S.M., 2008. Drug abuse and aggression between intimate partners: a meta-analytic review. Clin. Psychol. Rev. 28, 247-274.

Murphy, C.M., Winters, J., O’Farrell, T.J., Fals-Stewart, W., Murphy, M., 2005. Alcohol consumption and intimate partner violence by alcoholic men: comparing violent and nonviolent conflicts. Psychol. Addict. Behav. 19, 35-42.

Murray, R.L., Chermack, S.T., Walton, M.A., Winters, J., Booth, B.M., Blow, F.C., 2008. Psychological aggression, physical aggression, and injury in nonpartner relationships among men and women in treatment for substance-use disorders. J. Stud. Alcohol Drugs 69, 896-905.

Myerscough, R., Taylor, S., 1985. The effects of marijuana on human physical aggression. J. Pers. Soc. Psychol. 49, 1541-1546.

O’Farrell, T.J., Murphy, C.M., Stephan, S.H., Fals-Stewart, W., Murphy, M., 2004. Partner violence before and after couples-based alcoholism treatment for male alcoholic patients: the role of treatment involvement and abstinence. J. Consult. Clin. Psychol. 72, 202-217.

Parks, K.A., Hsieh, Y.P., Bradizza, C.M., Romosz, A.M., 2008. Factors influencing the temporal relationship between alcohol consumption and experiences with aggression among college women. Psychol. Addict. Behav. 22, 210218.

Raudenbush, S.W., Bryk, A.S., 2002. Hierarchical Linear Models: Applications and Data Analysis Methods. Sage Publications, Thousand Oaks, CA.

Raudenbush, S.W., Bryk, A.S., Congdon, R., 2001. HLM: Hierarchical Linear and Nonlinear Modeling. Scientific Software International, Chicago, IL.

Sayette, M.A., Wilson, G.T., Elias, M.J., 1993. Alcohol and aggression: a social information processing analysis. J. Stud. Alcohol 54, 399-407.

Smith, G.R., Babor, T., Burnam, M.A., Mosley, C.L., Rost, K., Burns, B., 1996. Substance Abuse Outcomes Module User's Manual. University of Arkansas for Medical Sciences, Little Rock, AR.

Smith, G.R., Burnam, M.A., Mosley, C.L., Hollenberg, J.A., Mancino, M., Grimes, W., 2006. Reliability and validity of the substance abuse outcomes module. Psychiatr. Serv. 57, 1452-1460.

Sobell, L.C., Maisto, S.A., Sobell, M.B., Cooper, A.M., 1979. Reliability of alcohol abusers' self-reports of drinking behavior. Behav. Res. Ther. 17, 157160.

Sobell, L.C., Sobell, M.B., Leo, G.I., Cancilla, A., 1988. Reliability of a timeline method: assessing normal drinkers' reports of recent drinking and a comparative evaluation across several populations. Br. J. Addict. 83, 393-402.

Straus, M.A., Hamby, S.L., Boney-McCoy, S., Sugarman, D.B., 1996. The revised Conflict Tactics Scales (CTS2): development and preliminary psychometric data. J. Fam. Issues 17, 283-316.

Tedeschi, J.T., Quigley, B.M., 1996. Limitations of laboratory paradigms for studying aggression. Aggress. Violent Behav. 1, 14.

Testa, M., Quigley, B.M., Leonard, K.E., 2003. Does alcohol make a difference? Withinparticipants comparison of incidents of partner violence. J. Interpers. Violence $18,735-743$.

Walton, M.A., Chermack, S.T., Blow, F.C., 2002. Correlates of received and expressed violence persistence following substance abuse treatment. Drug Alcohol Depend. 67, 1-12. 